\title{
More about Bernoulli Numbers
}

\author{
Nick Huo Han Huang
}

Received: November 19, 2015 / Accepted: December 12, 2015 / Published: March 25, 2016.

\begin{abstract}
Bernoulli Numbers are coded with Deterministic Redundancy of Arithmetic Operations, adding and multiplying or
\end{abstract} exponent, in Natural Number System. And based on the redundancy, a process for obtaining the Bernoulli Numbers is elaborated.

Key Words: Arithmetic Operation, Number Process, Repeating, Matrices, and Determinant.

Giving $\mathrm{s}_{0}=0$ and build the below number sequence.

$$
\mathrm{s}_{\mathrm{i}}=\mathrm{S}_{\mathrm{i}-1}+\mathrm{d}(\mathrm{i}), \mathrm{i} \in \mathrm{N}
$$

Then d(i) is also a number sequence and the sum of the first $\mathrm{n}$ terms of $\mathrm{d}(\mathrm{i})$ can be described as below, which is independent from the s sequence by which it is carried though.

$$
\sum \mathrm{d}(\mathrm{i})=\mathrm{S}_{\mathrm{n}}-\mathrm{S}_{0}=\mathrm{S}_{\mathrm{n}}
$$

Consider $\mathrm{d}(\mathrm{i})=\mathrm{i}^{\wedge} \mathrm{p}$, we have $\mathrm{s}_{\mathrm{n}}$ as below.

$$
\mathrm{s}_{\mathrm{n}}=\sum \mathrm{i}^{\wedge} \mathrm{p}
$$

By observation, the above sum of n-items can be expressed with a $(\mathrm{p}+1)$ 's polynomial of $\mathrm{n}$ as below.

$$
s_{n}=\sum a_{i j}{ }^{*} n^{\wedge} j, i, j=0 \text { to } p+1
$$

with $p+2$ items, $a_{i j}$ 's, $j=0$ to $p+1$, are the Bernoulli Numbers $^{<1>}$, and the below set of linear equations of $\mathrm{a}_{\mathrm{ij}}$ are formed.

$$
\sum \mathrm{a}_{\mathrm{ij}}{ }^{*} \mathrm{n}^{\wedge} \mathrm{j}=\sum \mathrm{i}^{\wedge} \mathrm{p}, \mathrm{i}=0 \text { to } \mathrm{n} \text { and } \mathrm{j}=0 \text { to } \mathrm{p}+1
$$

Which will be rational Diophantine (Non Deterministic) if $\mathrm{n}<\mathrm{p}+1$ or there are solutions for $\mathrm{a}_{\mathrm{ij}}$ for which at least $\mathrm{p}+2$ equations can be formed, i.e. $\mathrm{j}=0$ to $p+1$. And giving $p, n \in 0 \& N$ and $p<n$, without loss of generality, it is obvious to have the below results.

$$
\begin{gathered}
a_{0 j}=0 \text { for any } j=0 \text { to } p+1 \\
\sum a_{i j}{ }^{*} n^{\wedge}=\sum i^{\wedge} p \text { for } j=1 \text { to } p+1 \text { and } i=1 \text { to } n
\end{gathered}
$$

i.e. a $\mathrm{p}+1$-degree polynomial of $\mathrm{n}$ is enough to define $\sum \mathrm{i}^{\wedge} \mathrm{p}, \mathrm{i}=1$ to $\mathrm{n}$, the sum of $\mathrm{p}$-power of the consecutive natural numbers equal to and less than $\mathrm{n}$, The Deterministic Redundancy appears when $n>p+1$.

By analogy, $\mathrm{n}^{\wedge}(\mathrm{p}+1)$ can be a summation of p-degree polynomial of " $i$ " for $i=1$ to $n$. i.e. the below set of linear equations for $b_{\mathrm{pj}}$.

$$
n^{p+1}=\sum b_{p i}{ }^{*} j^{\wedge} i, i=0 \text { to } p, j=1 \text { to } n
$$

It is easy to observe that the solutions for $b_{p i}$ 's correspond to entries of the Pascal's Triangle, and the below equations.

$$
\mathrm{b}_{\mathrm{pi}}=(-1)^{\mathrm{p}+\mathrm{i}} *\left(\begin{array}{c}
\mathrm{i} \\
\mathrm{p}+1
\end{array}\right), \mathrm{i}=0 \text { to } \mathrm{p}
$$

And by expanding equations (c), we have:

$$
\begin{aligned}
\mathrm{n}^{\mathrm{p}+1}= & \sum\left(\mathrm{b}_{\mathrm{pp}} * \mathrm{j}^{\mathrm{p}}+\mathrm{b}_{\mathrm{pp}-1} * \mathrm{j}^{\mathrm{p}-1}+\mathrm{b}_{\mathrm{pp}-2} * \mathrm{j}^{\mathrm{p}-2}+\ldots\right. \\
& \left.+\mathrm{b}_{\mathrm{p} 2} * \mathrm{j}^{2}+\mathrm{b}_{\mathrm{p} 1} * \mathrm{j}+\mathrm{b}_{\mathrm{p} 0}\right), \mathrm{j}=1 \text { to } \mathrm{n} .
\end{aligned}
$$

That is,

$$
\begin{aligned}
\sum j^{p}= & {\left[n^{p+1}-\sum\left(b_{p p-1} * j^{p-1}+b_{p p-2} * j^{p-2}+\ldots\right.\right.} \\
& \left.\left.+b_{p 2} * j^{2}+b_{p 1} * j+b_{p 0}\right)\right] / b_{p p}
\end{aligned}
$$

In which, $\sum \mathrm{j}^{\mathrm{p}}$ can be expressed by a summation of $\sum \mathrm{j}^{\mathrm{k}}$ combination and $\mathrm{k}=0$ to $\mathrm{p}-1$ and is less then $\mathrm{p}$, which can be ordered down to $\mathrm{p}=0$, i.e. $\sum 1=n$.

And we have:

$$
\begin{gathered}
a_{p+1 p+1}=1 / b_{p p}=1 /(p+1), \\
a_{p+1 p}=-(-1) * b_{p p-1} /\left(b_{p-1 p-1} * b_{p p}\right)=1 / 2 .
\end{gathered}
$$

Actually, the Bernoulli Numbers $\mathrm{a}_{\mathrm{ij}}$ can be obtained by the below iteration process.

$$
\begin{gathered}
\mathrm{p}=0, \mathrm{~b}_{00}=1 \text {, then } \mathrm{a}_{11}=1 \text {, i.e. } \sum 1=\mathrm{n} \\
\mathrm{p}=1, \mathrm{~b}_{10}=-1, \mathrm{~b}_{11}=2 \text {, then } \mathrm{a}_{22}=1 / 2, \mathrm{a}_{21}=1 / 2, \text { i.e. } \\
\sum \mathrm{j}=\mathrm{n}^{2} / 2+\mathrm{n} / 2 \\
\mathrm{p}=2, \mathrm{~b}_{20}=1, \mathrm{~b}_{21}=-3, \mathrm{~b}_{22}=3,
\end{gathered}
$$

and we have the equations (e) as below.

$$
\sum \mathrm{j}^{2}=\left\{\mathrm{n}^{3}-\sum[(-3) * \mathrm{j}+1]\right\} / 3=\mathrm{n}^{3} / 3+
$$$$
\sum j-\sum 1 / 3=n^{3} / 3+n^{2} / 2+n / 2-n / 3=n^{3} / 3+n^{2} / 2+n / 6 \text {, i.e. }
$$

$$
\mathrm{a}_{31}=1 / 6, \mathrm{a}_{32}=1 / 2, \mathrm{a}_{33}=1 / 3
$$




$$
\mathrm{p}=3, \mathrm{~b}_{30}=-1, \mathrm{~b}_{31}=4, \mathrm{~b}_{32}=-6, \mathrm{~b}_{33}=4 \text {, }
$$

and then we have the equations (e) as below.

$$
\sum \mathfrak{j}^{3}=\left\{n^{4}-\sum\left[(-6) * j^{2}+4 * j-1\right]\right\} / 4=n^{4} / 4+\sum j^{2} * 6 / 4-\sum j+\sum 1 /
$$

$4=n^{4} / 4+n^{3} / 2+n^{2} / 4$, i.e.

$$
\mathrm{a}_{41}=0, \mathrm{a}_{42}=1 / 4, \mathrm{a}_{43}=1 / 2, \mathrm{a}_{44}=1 / 2 \text {. }
$$

Mathematics is there to be discovered and to be recognized.

\section{References}

[1] Nick Huang, Bernoulli Numbers \& Vandermonde Matrices, Journal of Mathematics and System Science, 6 (2) $2016,86-89$. 